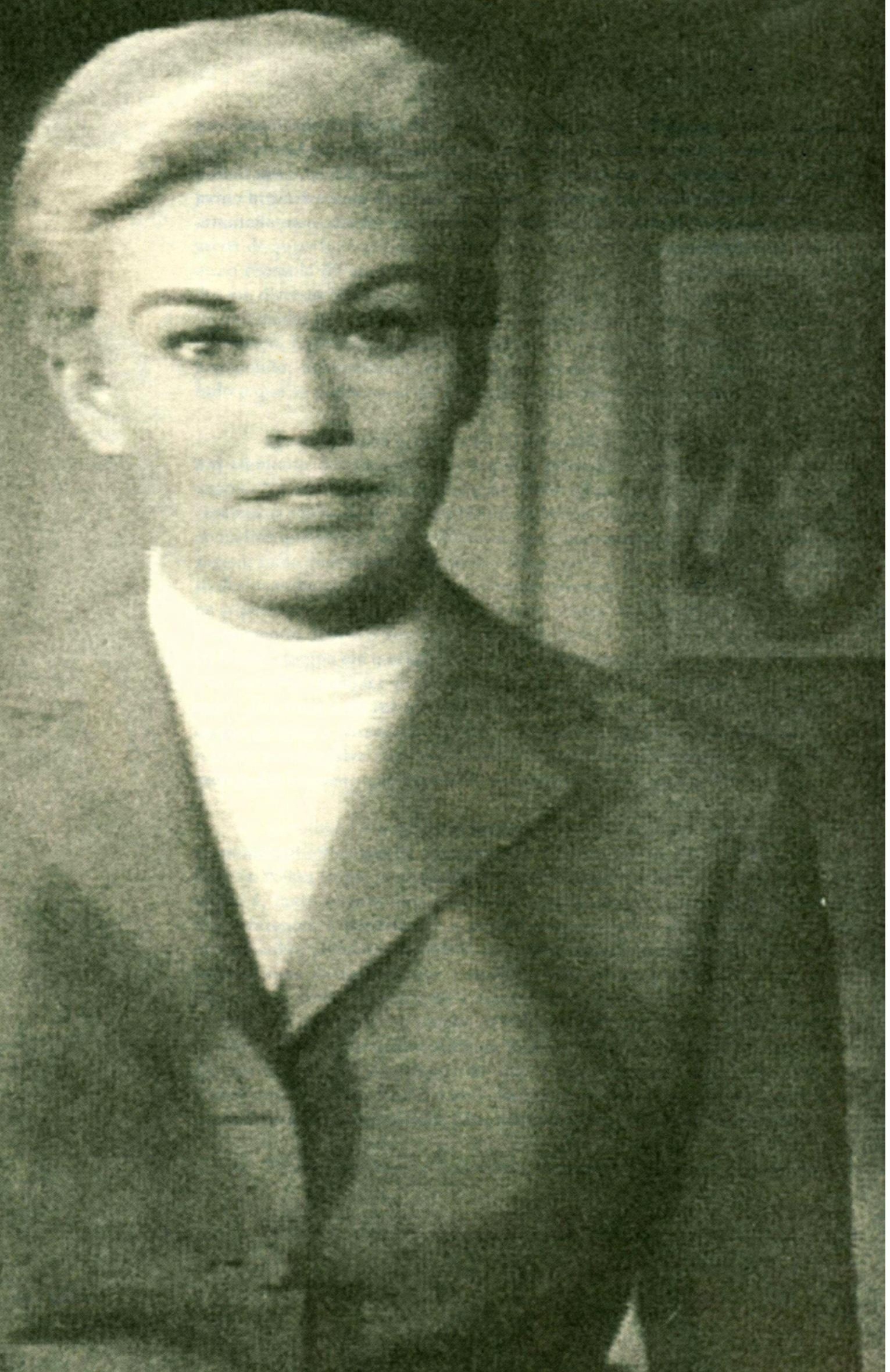




\section{Virginia H. A Aita ARTHUR DANTO: NARRATIVIDADE HISTÓRICA "SUB SPECIE AETERNITATIS" OU A ARTE SOB O OLHAR DO FILÓSOFO.}

Doutoranda em filosofia do departamento de pós-graduação da Universidude Federal do Rio Grande do Sul. e-mail: vhaa@tera.com.br

A questão controversa do "fim da arte" em Arthur C. Danto não é senão conseqüência imediata de uma certa teoria da estrutura da história no sentido de uma Bildungsroman do espírito. Segue-se dai um conceito filosófico de arte e uma concepção de crítica correlata enquanto "narrativa pessoal". O problema é que a narrativa modernista contra a qual Danto define sua prática crítica reintroduz aquela interpretação teleológica, e deverá então estabelecer sua diferença em relação à mesma. A soluçâo implica em reconsiderar a definição propriamente filosófica formulada no "The Transfiguration of the Commonplace", 1981, em termos de um deslocamento decisivo do argumento no "After the End of Art",1997, compatibilizando um essencialismo residual com o historicismo que avaliza sua crítica nos termos de uma concepção pluralista como enfranchisement da arte. de acirradas discussões, atuais (sobretudo com a publicação do "After the End of Art: Contemporary Art and the Pale of History”, 1997) e não tão atuais ${ }^{1}$, com respeito a este tema controverso, tematizado por diversos autores como Argan, Hans Belting e Gianni Vatimmo² para citar alguns, não pode ser compreendida em Danto senão como uma peça na complexa rede de interconexões que constituem sua teoria. Não remete imediatamente à formulação original de Hegel, mas antes supõe um conceito filosófico de arte e uma teoria da estrutura da história no interior da qual esta noção de fim da história ganha um sentido preciso. Uma peça de um quebra-cabeça cujo encaixe depende de um ajustamento prévio das teses que pressupõe, formuladas rigorosamente em termos filosóficos no The Transfiguration of Commonplace, 1981.

Em primeiro lugar a própria questão deve ser formulada inequivocamente, bem entendido, precisando o que entende pelo fim da arte no contexto da sua teoria. Trata-se do fim da arte como instituição histórico-social que iniciou no quattrocento e teve seu termo no século vinte, década de sessenta? O fim das narrativas históricas e da própria história da arte? $\mathrm{O}$ fim de um certo tipo de arte ou o fim da prática artística, do mercado e instituições adjacentes como um fato histórico manifesto, assim como a derrubada do muro de Berlin marcou ritualisticamente o fim comunismo como prática social na Alemanha Oriental, ou a queda da Bastilha o fim do Ancien Régime na França?

O que Danto entende como o fim da arte é uma radical descontinuidade ou ponto de inflexão - uma revolução na história da arte enquanto sucessão progressiva (e dialética) de períodos históricos, enunciada numa narrativa do seu desenvolvimento rumo à 'verdadeira' arte, precipitada pelo ready-
1. DANTO já penasara nesta questão do fin du arte desde a formulação da sua definição de atte no The Transfiguration of the Commonplace. Cambridge, Harvard UP, 1981, cf. prefácio vii. Mas a formula explicitamente pela primeira vez no artigo "The End of Art", incluido no volume The Death of Art, 1984, edita do por Berel Lang, na mesma época em que começa a escreter conto critico de ante para o The Nation, sugerindo um sintoma da sua alteração de perspectiva - um ajustamento do foco da jilosofia para n arte. Outros ensaios em que elabora essa noção são: "Approaching the End of Art", primeiro pro ferido como conferência no Whitney Nuseum en 1985 e publicado no The State of Art; "Narratives of the End of Art". (segue) 
In Encounters and Reflections: Art in the Historical Present. de

1991, e finalmente retoma este tema numa teoria refinada no After the End of Art

Contemporary Art and the Pale of History de 1997

\section{Cf. HANS BELTING}

The End of the History of Art. Chicago, Chicago,

UP, 1987; GIULIO CARLOARGAN. "A crise da arte como ciência européia". In Arte moderna. São Paulo, Companhia das Letras, 1992; GIANNI VATIMMO. "The End of

Modernity: Nihilism and Hermeneutics". In Post-Modern Culture.

Cambridge, Polity Press, 1988.

3. Cf Agui refere-se ao princípio da identidade dos indicerniveis formula-

do por Leibniz, e que generaliza como método filosófico por excelência, TC, p.35 e Connections to the World, p. 6-7.

4. Cf. DANTO

Embodied Meanings

Critical Essays and Aesthetic Meditations. New York, Noondaz Press,

Farrar, Strans and Gironx, 1994, p. 12

5. A. DANTO. After the End of Art:

Contemporary Art and the Pale of History.

Princeton, Princeton UP, 1997, p. 81-115 made de Duchamp e sobretudo pela celebrizada Brillo box de Warhol. A importância que assume este evento artístico deve-se ao fato desta obra revogar qualquer característica perceptiva que diferenciasse obras de meras coisas, com as quais eram visualmente coincidentes, desse modo introduzindo o problema filosófico fundamental dos objetos materialmente indiscerníveis ${ }^{3}$. Isso tem como efeito que todas as teorias estéticas tradicionais que discriminavam obras de arte com base em propriedades descritivas e formais tornam-se ociosas, já que as mesmas deixam de ser capazes de explicar o estatuto destes objetos insólitos "consensualmente" aceitos como arte.

Decretando assim a inaplicabilidade daquelas definições, traz para o primeiro plano a questão de um conceito filosófico de arte unicamente capaz de distinguir obras de meras coisas, restabelecendo aquela distinção categorial e indicando que esta diferença deve ser metafilosófica, construída sistematicamente. O que passa a ser decisivo é que a questão filosófica da natureza da arte é agora formulada no interior da própria arte (o que faz esta caixa de Warhol uma obra de arte e não a outra no supermercado aparentemente idêntica?). Mas o que considera seu grande insight ("com a força de uma revelação") é que isto não poderia ter surgido como um problema filosófico num momento anterior da história da arte ${ }^{4}$, mas então o que torna aquela configuração de circunstâncias históricas insubstituível e portanto necessária? Daí a inspiração hegeliana: supõe um movimento interno ao desenvolvimento histórico em cujo curso a arte atingiu a consciência da sua própria identidade (autoconsciência), e tornou-se sua própria filosofia. Que em Danto se traduz como uma lógica das estruturas históricas que permite estabelecer períodos de continuidade, caracterizados por uma gama de possibilidades e práticas significativas naquela estrutura narrativa (condensadas num estilo), mas que não exclue uma solução de descontinuidade em que o próprio estatuto da arte é posto em questão. Com isso, insiste o autor, a história da arte no ocidente não comporta mais nenhuma "evolução" ou desenvolvimento subsequente e a questão da natureza filosófica da arte, que o próprio percurso da história tornou enfim acessível, passa a ser problema dos filósofos desonerando desta tarefa os artistas, agora livres de quaisquer limites externos.

O fim é assim entendido como o propósito (end/purpose - Ende/Zwech) da história da arte consumado. Sobretudo a pintura a partir de Manet (ou como prefere Danto a partir de Gauguin e Cézanne), dramatizou este processo nas tentativas reiteradas de se redefinir, transgredindo esses limites. Levadas ao paroxismo, estas tentativas culminam e se exaurem com Duchamp e a Pop arte dos anos sessenta/setenta, em que a dissolução do objeto estético introjeta na própria obra o problema do seu estatuto, a reflexão sobre o seu conceito. Algo torna-se uma obra de arte por incorporar (embody) uma definição dela mesma. A tese sobre o fim da arte no "After the End of Art", é a consequêencia 
desse longo período do desenvolvimento da arte que chegou a seu termo com o episódio artístico das Brillo boxes de Warhol ${ }^{6}$, e que, segundo o autor, corresponde às narrativas históricas da arte (1) como mimese (de 1400 ao século dezenove) enunciada por Georgio Vasari, Ernst Gombrich e Robert Fry (este já ensaindo uma espécie de transição num formalismo estético capaz de dar conta da produção emergente do pós-impressionismo) e à narrativa modernista (de Manet, 1880, à década de sessenta) que teve como seu grande "mentor" Clement Greenberg. Isto significa que com a arte pós-histórica, o avant-garde dos anos sessenta/setenta, a história da arte consuma seu propósito tornandose sua própria consciência ("autoconsciência da sua identidade"), passando a coincidir com a filosofia da arte, e demonstrando desse modo a verdadeira natureza da arte ao tornar historicamente acessível o conceito filosófico de arte. Ora, esse momento de simbiose entre arte e filosofia é atavicamente hegeliano, e parece reeditar um movimento estrutural da autoconsciência na Fenomenologia do Espírito em uma passagem memorável citada por Kojève: "O verdadeiro é o devir de si, o círculo que pressupõe seu termo-final (Ende) como o seu objetivo (Zweck) que o tem como começo, e que só é objetivamente-real pelo desenvolvimento-realizador (Ausführung) e por seu termo-final" (Introdução à Leitura de Hegel, p. 496). É isso que significa quando afirma pontualmente que: "Uma grande narrativa terminou em 1964, na obra de Warhol em particular". E aqui começam os problemas, sobretudo para o tipo de crítica com base num formalismo substantivo conhecido como a marca de Clement Greenberg, num mundo da arte que se articulou em torno da atitude de Duchamp (a par de Joseph Beuys), reconhecido como seu generative thinker.

Todavia, e este é um ponto chave para compreender a démarche de seu pensamento, o que Danto pretende com a afirmação de um fim da arte, como vimos, conseqüência imediata de uma certa concepção filosófica da história da arte, interessa sobretudo pelas implicações que poderá acarretar para a sua definição de arte e a prática crítica que legitima, contextualizada num mundoda-arte pós-histórico e ipso facto pluralista.

III Ora, o que Danto pressupõe aqui é claramente uma interpretação teleológica da história da arte, enquanto uma sucessão de estágios num desenvolvimento progressivo com vistas a um fim, um clímax. Certamente, é à concepção teleológica da filosofia da história de Hegel que Danto está aqui se referindo. A história é assim entendida nos termos do gênero germânico do Bildungsroman - romance da formação e autodescoberta, história em que o herói atravessa vários estágios nos quais progride no caminho da autoconsciência. Mas aqui a história, na Fenomenologia do Espírito de Hegel, tem a forma de uma Bildungsroman no sentido de que o espírito (Geist) atravessa uma série de estágios para atingir não apenas o conhecimento de si mesmo (cons-

6. Danto rejeita ambas as narrativas com base no fato de que estas formulam de forma errada a guestão da natureza da arte: qual seja, o que a arte realmente ou essencialmente é em oposição ao que ela aparentemente é. Mas considerando que Danto também se considera um "essencialista" que se propõe a responder o que a arte realmente / essencialmente $e$, parece nos que, com efeito, respondem à questão certa de forma errada, i.e., com base na aparência fenomenológica. 
7. DANTO. After the End of Art. Op. Cit.,

p. 4.

8. Idem, p. 26.

9. Idem, ibidem.. ciência de si) mas daquilo que unicamente a sua realização na história torna verdadeiro, i.e., a história dos percalços, infortúnios, e desacertos humanos em relação à identidade abstrata, negativa do conceito. Analogamente, o que caracteriza o fim da arte não é senão o aparecimento de um certo tipo de autoconsciência.

O fim da arte é por conseguinte o fim de uma metanarrativa que implicava a idéia de um desenvolvimento visando um ponto máximo em que se consumava, tendo como sintoma a perda da confiança neste tipo de narrativa normativa que prescreve como as coisas devem ser. A arte depois do fim da arte é a resposta a esse ceticismo. Danto resume assim a aguda clivagem entre o moderno e o contemporâneo, cindidos por este momento extremo em que a arte coincide com sua própria autoreflexão filosófica: "É em parte o sentido de não pertencer mais a uma metanarrativa, registrando a si mesmo na nossa consciência em algum lugar entre a inquietação e o regozijo, o que marca a sensibilidade histórica do presente".?

IV. Ora, o problema aqui é que o tipo de teoria da história pressuposto tem como corolário um certo tipo de crítica, mas ao que parece, esta mesma concepção teleológica da história é também suposta pelas narrativas modernistas que derivam um tipo de crítica (os manifestos do Avant-garde, a crítica de Greenberg) a que Danto se opõe diametralmente. Ou seja, a teoria de Danto e as narrativas modernistas têm o mesmo parti pris teleológico com respeito à história da arte, o que exige qualificar a diferença entre as teorias da história que informam estes tipos de crítica e o modo como Danto interpreta esta perspectiva teleológica para salvar a consistência de sua teoria.

Assim, afirma que uma vez que se admita que a arte, tornando-se sua autoconsciência, tenha chegado a um fim, não se acha mais subordinada à necessidade do desenvolvimento histórico e por conseguinte o tipo de crítica apropriado seria outro que aquele correlativo "às visões da história que identificam certas formas de arte como historicamente compulsórias/imperativas". ${ }^{8}$ Este é precisamente o ponto de disputa - narrativas "que identificam certas formas de arte como imperativas". Assimila a concepção da história destas teorias àquela que o próprio Hegel, num mau passo, professa com respeito ao "mundo histórico", que somente reconhece e inclui certas regiões em certos momentos, banindo o resto (drop outs como a África ou a Sibéria) para fora da "fronteira da história" (the pale of history). Contrasta a sua teoria da estrutura da história da arte com estas teorias, proeminentes na era moderna, que como Hegel definem somente certos tipos de arte como historicamente relevantes, excluindo o resto como "fora do mundo histórico". Para Malevich, os excluídos eram os que não se alinhavam ao cubo-futurismo, para os dadaístas de Berlim só subsistiam os adeptos da Machinekunst de Tatlin, para Greenberg ficavam 
relegados ao silêncio os que não se convertessem à pureza da pintura, que refletindo-se sobre si mesma passava a não descrever o mundo mas a tematizar o próprio meio, as próprias condições de representação, num inward turn tipicamente moderno. Esta parece então ser a chave do problema: caracterizar a prática crítica das narrativas modernas numa relação específica com os pressupostos filosóficos que as legitimavam fazendo coincidir filosofia com "uma estética".

As narrativas modernistas, desafiadas a substituir o paradigma clássico da mimese por um novo paradigma, faziam de cada movimento específico a busca da "verdade filosófica da arte" (o que a arte essencialmente é) excluindo o que não fosse coextensivo a esta essência. Sem dúvida, isto pressupunha uma perspectiva teleológica da história da arte que convergia para um, 'estado final' que coincidia com a verdadeira essência da arte. Neste sentido, sublinha Danto, cada um desses movimentos pretendia ser a manisfestação privilegiada desta essência, em termos de uma "narrativa da recuperação, do descobrimento, da revelação de uma verdade que tinha sido perdida ou obscuramente reconhecida". ${ }^{10}$

É este parti pris que Clement Greenberg, crítico que articula a narrativa do modernismo, exemplifica magistralmente no ensaio "Para um novo Laoconte" - uma apologia histórica da arte abstrata onde postula que o abstracionismo, em virtude da "lógica do desenvolvimento da arte", adquire necessidade histórica assumindo a forma de um imperativo (a única "via verdadeira" para a arte)."

Do mesmo modo, todos os movimentos do século vinte, do Fauvismo e Cubismo à Malevitch, Mondrian, Reinhardt, preconizam um único estilo como verdadeiro, tornando incompatíveis e irreconciliáveis entre si as diversas narrativas históricas. Isto é patente na declaração de Ad Reinhardt: "O único objetivo de cinqüenta anos de arte abstrata foi apresentar-a arte-como-arte e como nada mais...fazendo-a mais pura e mais vazia, mais absoluta e mais exclusiva (= excludente)". ${ }^{12}$

A diferença fundamental que Danto pretende estabelecer entre a sua versão da filosofia da história da arte que chegou a um fim e estas teorias da história da arte que identificam certas formas de arte como historicamente imperativas, consiste em aceitar o percurso teleológico da história da arte até um fim no qual atinge sua autoconsciência, a definição filosófica, como um tipo de essência trans-histórica da arte, que é invariável e allinclusive, mas que nunca se atualiza numa forma particular. Mas rejeita como inconsistente, ao contrário daquelas, a identificação desta essência com um estilo particular de arte, implicando a exclusão de qualquer outro estilo/narrativa como falso. Rejeita qualquer tipo de imperativo histórico que atribua necessidade a uma narrativa em detrimento de outras, subtraindo-lhe seu caráter contingente e
10. Idem, p. 28.

11. CLEMENT

GREENBERG. The

Collected Essays and Criticism. vol.I, Chicago, Chicago UP, 1993

12. BARBARA ROSE (ed.) Art-as-Art: The selected Writings of Ad Reinhardt, Berkeley, California, UP, 1991, p. 53 . 
13. DANTO. After the End of Art. Op. Cit,.

p. 14

14. Idem, p. 30-31 \& HEGEL.

Aesthetics, II.

Oxford, Claredon UP,

1975

15. O que torna a teoria da arte corolario da sua filosofia é a homogeneidade do método, qual seja, o "método dos indiscerniveis". (segue) hipostasiando-a como critério universal. Rejeita a substituição da filosofia da arte por uma estética substantiva. Apenas nisto reside a diferença entre a sua teoria da história da arte, e aquela que legitima outro tipo de crítica (nomeadamente a de Greenberg). Declara: "O que Greenberg fez foi identificar um certo estilo local de abstração com a verdade filosófica da arte, quando a verdade filosófica uma vez encontrada, teria de ser consistente com a arte aparecendo em todos os modos possíveis". ${ }^{33}$

Por conseguinte, o equívoco fundamental não era supor uma "essência trans-histórica", invariável (sempre a mesma e universalmente válida) pois desindexada historicamente, mas precisamente em "determiná-la" numa narrativa histórica particular. Ou ainda como insiste Danto, em tomar a filosofia da arte como crítica de arte. A conseqüência paradoxal destas "narrativas absolutizadas" é que produziram uma "leitura a-histórica" da história da arte segundo a qual toda a arte deveria ser essencialmente a mesma.

$O$ seu diferencial consiste portanto em considerar o fim da arte unicamente como a emergência da "consciência da natureza filosófica da arte", que não se identifica com nenhum único estilo particular, mas como conceito filosófico e universal deve abranger toda e qualquer espécie de arte. Segundo o autor, esta definição se encontra literalmente na seguinte tese de $\mathrm{Hegel}^{14}$ sobre o fim da arte, a saber:

"A arte considerada na sua mais elevada vocação, é e permanece para nós uma coisa do passado. Assim ela perdeu para nós a vida e a verdade genuínas, antes transferindo-se para nossas idéias em vez de manter sua antiga necessidade na realidade e ocupando seu mais alto grau. O que é agora despertado em nós por obras de arte não é apenas a satisfação imediata, mas nosso juízo, uma vez que sujeitamos à nossa consideração intelectual (i) o conteúdo da arte, (ii) os meios de apresentação ( forma) da obra de arte, e a adequação ou inadequação de um ao outro. A filosofia da arte é portanto de maior necessidade em nossos dias que à época em que a arte por si própria produzia plena satisfação. A arte nos convida à consideração intelectual, e isto não com o propósito de criar arte, mas de conhecer filosoficamente o que a arte é."

A arte então já não era mais a manifestação sensível e privilegiada da idéia, do espírito absoluto, como no seu apogeu na escultura clássica em que aquela adequacidade era "imediata", não se baseava mais numa tácita afecção dos sentidos, mas interpelava o juízo, e assim subvertia as crenças filosóficas sobre o que é a arte, pois já não coincidia simplesmente com a sua aparência sensível. Nestes termos, Danto distingue sua interpretação teleológica que pretende reeditar a solução hegeliana, daquela da narrativa modernista por ele diagnosticada como um erro de positio quaestionis. Ou seja, o que a arte é, é uma questão filosófica que não pode ser formulada em termos da distinção aparência/essência, mas sob a forma propriamente filosófica da indiscernibili- 
dade dos idênticos (para Danto esta é a forma de todas as questões filosóficas) ${ }^{15}$. Ora, uma vez que a verdadeira forma desta questão não pôde ser formulada até que existissem obras de arte indiscerníveis de seus correlatos materiais num certo momento da história da arte, pode-se dizer que a filosofia da arte é "refém da história da arte".

Contudo, como observa Nöel Carrol, um dos mais afinados críticos de Danto, arguto defensor das narrativas históricas como condição imprescindível da identificação de obras de arte ${ }^{16}$ aqui incide uma inconsistência. Afirma que uma vez que Danto reconhece o problema dos indiscerníveis instanciado na Brillo box de Warhol, que unicamente permite formular a definição da arte nestes termos por ser materialmente indistinguível de meras coisas, por que precisaria anexar a explicação teleológica da história de Hegel para fundamentar esta definição? Isto parece, além do mais, um expediente ad hoc que compromete sua teoria até então sustentável, pois se o problema dos indiscerníveis surge como a condição necessária para a formular a definição de arte, Hegel, através do desenvolvimento da história, chega a uma definição muito semelhante sem confrontar a questão da indiscernibilidade.

Em contrapartida, Danto insiste que a questão dos indiscerníveis não poderia ter aparecido num outro momento da história, senão com a Pop arte dos anos sessenta, e isto torna necessário uma certa estrutura interna da história da arte em que uma narrativa da autoconsciência desdobrando-se no tempo fosse condição da emergência da definição filosófica. A única resposta plausível para este deslocamento da sua teoria anterior baseada numa definição filosófica (definição real) segundo condições necessárias e suficientes, e que justificaria esta manobra, ao menos ao que parece, é que a teoria da arte de Hegel não é uma teoria filosofica stricto sensu (o que implicaria o método filosófico dos indiscerníveis) mas um tipo de historicismo, e é precisamente esta passagem que Danto está buscando para legitimar sua crítica. Uma forma de crítica que, sem limitar-se por qualquer definição que inclua um imperativo, histórico (uma narrativa histórica hipostasiada como estética filosófica e por conseguinte trans-histórica), uma vez dada a distinção ontológica entre arte e não arte, opera livremente, bem entendido, reflexivamente no território da contingência, da historicidade fenomenológica ou do presente histórico da obra para estabelecer (crítica e reflexivamente e não dogmaticamente) mediante uma interpretação crítica, seu estatuto de arte. Crítica rigorosamente antidogmática. O que faz pressentir aqui uma ascendência Kantiana, ao que me parece, tão implicitamente reguladora quanto denegada, mas isso é assunto para outra discussão.
Este não é somente um dispositivo da filosofia da arte mas antes da própria filosofia (enquanto discurso de segunda ordem), que tal como Danto a concebe, é gerada por problemas de indiscemibilidade que caracterizam a natureza peculiar dos problemas filosóficos os quais não são equacionados em termos do critério de verificabilidade, i.e., das condições empíricas de decidibilidade dos seus enunciados. Este é o caso do problema da realidade do mundo exterior, nas primeiras meditaçôes de Descartes, formulado cono a indiscernibilidade do sonho e da experiência do mundo; o problema da causalidade como a impossibilidade de distinguir entiricamente entre dois cursos de eventos a conjunção constante de estados do mundo e a conexão necessária de causa e efeito em Hume; o problema de separar a ação moral da meramente prudente (agir pelo princípio, ou meramente em conformidade com o principio) sen qualquer diferença observável, em Kant; ou ainda a ocorrência histórica que origina a filosofia da arte como uma questāo interna d arte - de dois objetos perceptualmente indiscerniveis, um a "Fonte" de Marcel Duchamp, outro um simples mictório. 
16. Cf. NÖEL CARROLL. "Historical Narratives and the Philosophy of Art". In The Journal of

Aesthetics and Art Criticism. 51:3 Summer 1993. Neste artigo expõe sua própria teoria da arte que consiste sumariamente em dispensar uma definiçāo real, segundo condições necessárias e conjuntamente suficientes e propor um outro método para identificar obras de arte baseado unicamente nas narrativas históricas que então caracteriza como identifying narratives.

17. DANTO. After the End of Art, Op. Cit., p. 195. Cf. HEGEL, Aesthetics, Op. Cit., vol.I, p.il.

18. Cf. NELSON GOODMAN. Languages of Art. Indiana, Hackett Publishing, 1976, p 85-95. Especialmente cap. II e VI, onde apresenta sua teoria da metáfora e os "sintomas do estético". Ver também de GOODMAN. Ways of

Worldmaking, Indiana, Hackett Publishing, cap, II, IV, VI

19. DANTO. The Transfiguration of the Commonplace. Op. Cit., p. 189-197. tiplicam quando ajustamos o foco sobre a definição de arte aí apresentada. Limito-me aqui a enumerar alguns destes críticos como Mark Rollins, Whitney Davis, Michael Kelly, David Carrier, além de Nöel Carrol, cujas respectivas análises oscilam entre acusar Danto de regredir a uma sujeição ou aprisionamento das artes sob o conceito filosófico, ou noutro extremo, de esvaziar esta definição em favor de um historicismo que emancipe sua crítica de qualquer injunção normativa. A solução intermediária de compatibilizar essencialismo com historicismo me parece a mais produtiva, mas dependerá de sua engenhosidade para fazer os ajustes necessários e converter uma aparente aporia num argumento consistente, articulando sua noção de crítica a partir da reflexão filosófica sobre a estrutura metafísica da obra. Vejamos sua estratégia.

Danto recorta na passagem supracitada sobre o fim da arte de $\mathrm{Hegel}^{17}$, a seguinte definição:

"O que é agora despertado em nós por obras de arte não é mais apenas a satisfação imediata, mas nosso juízo, uma vez que sujeitamos a nossa consideração intelectual (i) o conteúdo da arte, (ii) os meios de apresentação (forma) da obra de arte, e a adequacidade ou inadequacidade de um ao outro".

Ainda que pretenda ter aqui uma definição essencialista (= stricto sensu filosófica mediante condições necessárias e conjuntamente suficientes) é contudo apenas parcialmente essencialista (definição não suficiente), tendo em vista compatibizar com um historicismo apropriado de Hegel. Não precisa de nada além dessas duas condições, declara, para "mapear a anatomia da crítica". Para ser uma obra de arte uma coisa qualquer precisa tão somente (i) ser sobre algo (aboutness), i.e., ter um conteúdo semântico; (ii) e ainda deve incorporar (embody) seu conteúdo, significado, o que implica em encontrar um modo de "apresentação"(Darstellung, exhibitio) ou uma forma (da representação ou meio artístico) apropriada a um certo conteúdo, não no sentido da mera designação, mas para além de considerações sintáticas e semânticas; é o modo como o conteúdo é apresentado para significar algo sobre esse conteúdo que importa, a obra assim apresenta seu significado ao apresentar o modo no qual ele se apresenta, i.e., como expressão. Expressão aqui entendida como transferência ou "exemplificação metafórica", uma noção originalmente formulada por Nelson Goodman ${ }^{18}$, que Danto já no "Transfiguration" refina na sua semântica da representação plástica ${ }^{19}$. Nos diz assim, que enquanto representação transfigurada - coisas convertidas em obras de arte mediante uma crítica qua interpretação (processo transformativo e constitutivo do status de arte) - obras de arte ficam definidas pela estrutura intencional da metáfora: são expressão (exemplificação metafórica) singularizada num estilo. $O$ estilo, conceito complexo que não interessa aqui analisar, é numa fórmula compacta o próprio homem, i.e., como modo de ver e corporificar o mundo, um modo de representar o mundo menos o mundo, antes o como do que o que, um algorítimo 
pois o homem, como a soma total de suas linguagens, é ele mesmo um signo ${ }^{20}$.

Apresentada no último capítulo desse livro (After the End of Art), a sugestão implícita é que esta definição tão abstrata (não uma definção real capaz de individuar por si obras de arte) é que contém a chave para o seu historicismo, que sobredeterminando sua teoria filosófica da arte resulta na tão cara enfranchisement da arte, indicando uma possível compatibização com um essencialismo atenuado e dando sustentação teórica a sua crítica. A definição filosófica assim torna-se formal e abstrata, já que não contém como condição necessária uma narrativa histórica que lhe confira conteúdo, sendo assim capaz de compreender qualquer tipo de arte (sem contudo poder individuar nenhuma obra particular), uma classe cuja extrema heterogeneidade da sua extensão (um conjunto logicamente aberto de coisas que não compartilham nenhuma propriedade comum aparente para serem membros de uma classe) levou Wittigenstein $^{21}$ a sugerir sua indefinibilidade com base em propriedades descritivas, pois assim como jogos, apresentavam no máximo "semelhanças de família". Apenas o arcabouço ou estrutura metafísica da arte enquanto signo estético/representação transfigurada e nestes termos categorialmente distinta de coisas ou simples representações, é o que Danto nos concede cedendo espaço à interpretação historicamente declinada não como condição necessária mas contingente, pois só instituída criticamente.

A crítica de Nöel Carroll com respeito a esta nova definição deve-se ao fato de ser uma definição nominal, que sequer apresenta condições necessárias e conjuntamente suficientes para individuar obras de arte, sobretudo em razão de ter suprimido a referência necessária às narrativas históricas, embora este seja o principal tópico do livro. Constitui portanto um deslocamento radical das obras anteriores, sobretudo no "The Artworld", e no "The Transfiguration of the Commonplace", em que as teorias do mundo-da-arte e narrativas históricas que estas geram tinham a função de legitimar obras de arte, e portanto constituía uma condição necessária do status de arte que a obra fosse uma instância dessas teorias. Por isso mesmo, uma ampola contendo ar parisiense era considerada arte no século vinte pelos adeptos de Duchamp, mas dificilmente seria assim no tempo de Giorgio Vasari. Identificar algo como obra implicava em situá-la num mundo-da-arte historicamente contextualizado, referindo-a a uma narrativa histórica específica. Wölfflin já havia percebido isto:

"Mesmo o talento mais original não poderia operar além de certos limites que eram fixados para ele pela data de seu nascimento. Nem tudo é possível em todos o tempos, e certos pensamentos só podem ser pensamentos em certos estágios do desenvolvimento". 22

Mas mesmo conferindo a essas teorias e narrativas uma importância substancial, Danto não as inclui como necessárias na sua definição de arte. Mas por que esta guinada tão radical? Para Nöel este é um passo compromete-
20. idem, ibiden.

21. Assim como jogos, só admitem uma semelhança de familia. Cf. WTTGENSTEIN L.Investigations. (Trad. G. E. M.Ascombe). New York, Prentice Hall Press, 1999, seç. 66 - 67.

22. WOLFFLIN. Principles of Art History: The Problem of the Development of Style in Later Art. New York, Dove Publications, s.d., ix. 
23. NÜEL CARROLL. Op.cit. p. 380. dor, pois sem a referência necessária às narrativas históricas, a distinção entre meras coisas e obras de arte, o argumento dos indiscerníveis, se evapora. A mera exigência de significar algo e incorporar seu significado, num modo de apresentação apropriado, são apenas condições necessárias mas não suficientes para individuar obras de arte. Esta permissividade da nova definição incluiria como obra de arte coisas que não são arte, como artefatos de design, embalagens, carros esporte, etc., que apresentam ou corporificam na sua forma características e funções que possuem, tal como eficiência, velocidade, economia. E precisamente as Brillo boxes seriam o exemplo mais devastador, pois sem uma teoria da arte e respectiva narrativa que a localize no ambiente da história da arte, não poderiam ser distinguidas das meras embalagens nas prateleiras do supermercado. Unicamente quando referidas a uma narrativa indexada historicamente, caixas de papelão podem ser consideradas obras de arte. Isto era possível na sua teoria filosófica do "The Transfiguration", que claramente fornecia este critério para distinguir obras de coisas em geral.

A aparente vantagem de suprimir as teorias da arte e respectivas narrativas é que se desobriga de qualificar a diferença entre estas e outros tipos de narrativas e teorias como as da ciência. Mas o que parece ser a razão mais forte para essa supressão segundo Carroll $^{23}$ é que são justamente estas narrativas que originam o limite da história (the pale of history), expressamente abolido com o fim da arte, na arte pós-histórica. Haveria então uma espécie de convivência pacífica, ecumênica, de teorias da arte e narrativas, sem qualquer imperativo histórico que as tornasse imcompatíveis ou excludentes. Um estado de coisas que Warhol traduz com precisão: "Como você pode dizer que um estilo é melhor do que outro? Você deve poder ser um expressionista abstrato na próxima semana, ou um artista Pop, ou um realista sem sentir que desistiu de alguma coisa". Ao contrário, é o caráter excludente o ônus das metanarrativas, que como o "mundo histórico" de Hegel, excluem tudo o que extravasa suas fronteiras, ou confronta seus princípios, e que a narrativa modernista, na crítica de Greenberg, claramente ilustra ao banir Duchamp e o surrealismo do seu ângulo de visão.

VII Mas, ao contrário do que aponta Carroll, não me parece tratar-se de uma supressão, o que fica evidente no "After the End of Art", onde as narrativas históricas amplamente discutidas continuam a desempenhar um papel fundamental, só que noutra relação com o conceito filosófico de arte. Isso nos leva à questão crucial da disjunção e complementariedade entre filosofia e crítica de arte, a qual se define em oposição à universalidade da primeira como uma narrativa pessoal, escritura-crítica, que reintroduz a diferença e reconstrói a singularidade da obra, circunscrendo-a na rede de suas matrizes histórico-causais. A sua teoria filosófica da arte antes formulada no "The transfiguration 
of the Commonplace", a sua obra rigorosamente filosófica sobre arte, fornecia o elenco de condições necessárias e (conjuntamente) suficientes para identificar uma obra de arte: o "método dos indiscerníveis", segmentado em cinco estágios ou condições de possibilidade a serem satisfeitas por uma obra de arte qualquer, a saber: 1) que são sempre sobre alguma coisa, têm conteúdo semântico; 2) projetam um ponto de vista ou atitude sobre aquilo que são sobre; 3 ) projetam este ponto de vista por meio de elípses retóricas/ metáforas; 4) requerem uma interpretação que é constitutiva da sua identidade (artística); e finalmente, (5) esta interpretação é historicamente localizada num mundo da arte pertinente.

Deriva então dessa teoria que parece mais adequada ao moderno já que se fecha num elenco de condições suficientes para indentificar obras, uma teoria allinclusive que deve aplicar-se universalmente a todo tipo de arte medieval, oriental, ocidental, abstrata, figurativa, pintura, instalação, performance, vídeo, etc., pois pretende articular o próprio conceito de arte como uma categoria ontológica distinta. Esta definição enxugada torna-se agora ainda mais genérica sem implicar uma narrativa histórica como condição necessária e em razão disso não impõe uma agenda crítica (critérios particulares que permitam individuar obras). Isso confere à crítica uma liberdade irrestrita, já que a filosofia não prejulga sobre particulares.

Daí segue-se a disjunção fundamental para o pensamento de Danto, entre sua filosofia e sua prática crítica, na medida em que aquela teoria, enquanto metafilosófica, não trata senão da estrutura metafísica da obra, e assim não restringe de modo algum o território da crítica, a qual será complementar à filosofia no sentido de unicamente permitir identificar obras mediante uma interpretação complexa que reintroduz as teorias e narrativas do mundo da arte capazes de indentificá-las. A questão do fim da arte interessa aqui sobretudo com respeito às implicações desta tese para essa prática crítica como o fio condutor para a elaboração de um outro modus operandi compatível com outro cenário artístico.

Se para Greenberg, com o fim da arte e a descoberta da sua essência, seguia-se a partir daí um congelamento do estilo abstrato como estilo canônico, o fim da arte se distingue aqui na medida em que a essência ou definição filosófica da arte é compartilhada indiscriminadamente por qualquer tipo de arte, pois nada exemplifica de forma privilegiada esta essência que é absolutamente genérica. Ao contrário, o que faz uma obra enquanto tal são seus acidentes, suas diferenças que variam com o artista e com os períodos e localização históricos, e é irrelevante tentar exemplificar essa essência abstrata (subsiste o hiato entre o caso e a regra, o universal e o particular, o ideal e o empírico). Para Danto a ausência de uma agenda crítica, de uma norma ou imperativo estético assegura uma abrangência irrestrita que inclui tanto trabalhos formalis- 
24. JEAN-FRANÇOIS CHEVRIER. "Between the Fine Arts and the Media (The German Example: Gèrhard Richter)". In: Photography and Painting in the Work of Gerhard Richter. Barcelona, Llibres de Recerca, 2000, p.35. tas, quanto o decorativo, o literário, o político, e a qualidade estética (critério exclusivo para críticos como Hilton Kramer) será apenas mais uma das características da obra, e não condição essencial. Portanto a estrutura da história da arte sob o aspecto do seu fim autoriza um pluralismo que traz à superfície uma espessura insuspeitada, e antes interdita, das realidades artísticas.

Mas a atitude mais característica da arte pós-histórica, em boa parte produto do experimentalismo prodigioso dos anos setenta e ainda do background disponível do avant-garde das primeiras décadas do século vinte, parece ser a apropriação de imagens, imagens ready-made, cuja identidade e significado estabelecidos, uma vez deslocados e impregnados de conotações, são transfigurados numa nova identidade. A questão da reprodução da realidade figurativa na mimese ou da tematização das condições de representação, a superfície estética (o plano, o pigmento) como essência da obra, parece então dar lugar a uma crítica da produção da imagem, pondo em questão o estatuto artístico do signo como arte sem com isso implicar uma única direção narrativa, mas antes reintroduzindo criticamente narrativas diversas e igualmente significativas. A obra de Gerhard Richter, sobretudo seu uso da fotografia e a referência à pintura histórica, são sem dúvida emblemáticas e bem mais significativas que os portraits de Warhol, já que conjugam um approach pop do uso da media com uma formação clássica de pintura de atelier em que a memória hístórica da pintura é atualizada. Justifica sua referência ao romantismo e particularmente à pintura de Caspar David Friedrich, argumentando que não são coisas de um passado extinto, apenas as circunstâncias e ideologias em que foram criadas, e assim ele faz 'pinturas históricas' porque o presente não está limitado ao espetáculo da contemporaneidade, mas a história, agora disponível, é parte dele. Para Richter as razões do seu recurso à fotografia são claras: uma delas, a mesma de Matisse, apenas um instrumento para retratar. Segundo o artista, “isto impede a estilização, ver 'falsamente' ou dar uma interpretação extremamente pessoal ao assunto" ${ }^{24}$, a outra razão e a mais original consiste em que: "Uma foto já é um pequeno tableau, embora ainda não completamente. Este caráter é exasperante e o impulsiona a querer transformá-lo definitivamente numa pintura". Assim Richter transfere a 'lógica da fotografia' para a pintura que não é senão um tableau fotográfico. E acrescenta a afirmação desconcertante: "Não quero imitar uma fotografia. Quero fazer uma. Na verdade estou fazendo fotos com meios diferentes e não pinturas que lembrem uma fotografia".

Para Danto, a prática crítica compatível com o cenário contemporâneoconsistirá sobretudo em conceber obras de arte como "embodied meanings" (significados coporificados), embutindo estruturas metafóricas que exigem a interpretação da crítica, e fazem a tarefa do crítico dupla: identificar por meio de uma interpretação o que a obra significa, seu conteúdo, e então demonstrar 
de que modo este significado é corporificado, elipticamente apresentado nesta obra. Portanto, ao contrário das estéticas formalistas, não está minimamente interessado nos aspectos formais, perceptuais da obra a menos que estes se interconectem com o significado de tal modo que não sejam senão a corporificação, o modo de apresentação desses mesmos significados na obra. E esses significados (narrativas implícitas) vêm do mundo em que o artista vive, decalcam uma forma de vida, incluindo o mundo-da-arte pertinente que constitui seu ambiente institucional mais próximo, são, por conseguinte, historicamente indexados.

Identificar obras mediante uma interpretação que resulta numa crítica não poderá absolutamente resolver-se mediante um elenco de predicados descritivos, "aquilo que o olho alcança" (optical unconscious!), mas requer fundamentalmente um tipo de teoria e assim um mundo-da-arte (uma atmosfera saturada de teorias e crenças históricas) é imprescindível para que uma obra como a Brillo Box ou a Fonte sejam identificadas. Segundo o autor, o formalismo ou "visualismo" de Greenberg é cada vez mais inaplicável no mundo da arte de hoje, onde o que eram antes artes visuais são hoje "significados corporificados". Um caso emblemático são as fotografias de Mapplethorpe censuradas por serem "excessivamente belas", perspectiva que Danto subverte ao investigar aí o que esta beleza tem a ver com seu conteúdo e que diferença faria se fossem não belas, mas sórdidas. Tampouco exclui arte por ser política, isto seria como criticar arte por ser religiosa, sem compreender que ela não teria as qualidades estéticas que tem se não fosse por seu conteúdo e intenção religiosos. $\mathrm{O}$ tipo de crítica que Danto propõe alinhada ao pluralismo do cenário contemporâneo, resulta como consequiência da análise da estrutura da história da arte, o fim da arte, e da disjunção entre filosofia e crítica de arte requerida. Crítica que não pode mais ser subserviente a uma agenda e tampouco a um critério exclusivo como "qualidade estética". Assim contrapõe a alternativa de uma "crítica de arte inferencial", como a sugerida por Michael Baxandall, que consiste em primeiro ver obras como pressupondo explicações, e então inferindo a melhor explicação de porque elas têm precisamente a forma que têm em termos de suas circunstâncias e diferenças históricas e causais, o que é também o seu modus operandi. Kant diria, propriamente, uma maneira adequada ao gosto e à reflexão estética e não um método entendido como doutrina demonstrada (CF. $\mathrm{KU}, \$ 60)$. Danto descreve a crítica como a arte de reconstruir um enigma, iluminar a obra sem confiscar seu mistério, percorrendo-a sem explicitá-la discursivamente, contemplando-a como um claro enigma. Assim olha a obra até começar a vê-la problematicamente, como contendo algo implícito a ser compreendido. O relato da elaboração de sua crítica sobre uma exposição do século dezesseis de Hendrik Goltzius ${ }^{25}$, torna clara sua estratégia. Era um desenho à bico de pena sobre tela, onde a linha desenhada era dissimulada como se
25. Danto. Embodied Meanings: critical essays and acsthetic meditations. New York, Noonday Press, Farrar, Straus, and Giroux, 1994, p. 14. 
26. Hostinato (sic) rigore era a divisa de Leonardo da

Vinci. Cf. VALERY. "Introduction à la Méthode de Leonard da Vinci". In: Oeuvres. Paris, Gallimard, 1959 t. Pleiade, p. 1155, nota

27 Cf. PAUL VALERY, Cahiers. Paris, Galliward, 1973

28. DANTO. Beyond the Brillo Box: the visual arts in post-historical perspective. New York, Noonday Prees, Farrar, Straus, and Giroux, 1993, p. 229 . fosse gravada. A questão que emergiu para ser explicada era o que poderia explicar esta escolha/uso do meio? E que por fim lhe pareceu que a associação que Goltzius queria evocar com aquele imenso desenho à nanquim era o fato dele não poder ser retocado, apagado, repintado ou sobreporem-lhe pinceladas. Era para ser percebido como uma obra de extrema destreza e de um virtuosismo quase miraculoso. A regularidade das linhas paralelas como que gravadas, seu afinar e espessar conduziam a esse efeito. Este aspecto revelou muito acerca de Goltzius - seu padrão, sua época, bem como o formato de crítica/apreciação na corte de Rudolf II de Praga, mas sobretudo esta análise tornou acessível esta obra de um mundo tão descontínuo ao nosso.

Mas são em última análise notas biográficas que permitirão traçar seu diferencial como um filósofo que se tornou crítico de arte. Isso porque o irreverente crítico do The Nation, com publicações regulares na Artforum, no The Journal of Aesthetics and Criticism, British Journal of Aesthetics, Journal of Philosophy, e inúmeros outros periódicos de crítica e filosofia da arte, bem como livros recentemente publicados reunindo seus ensaios sobre arte, não oblitera o eminente filósofo que se notabilizou nos meios acadêmicos sobretudo com sua original teoria da ação e sua filosofia da história (Analytical Philosohy of History) que o levou a se descobrir tardiamente admirador confesso de Hegel. Compreender seu pensamento sobre a arte implica assim em somar ao crítico o filósofo. Produto inadvertido de uma rara confluência (ele mesmo se confessa surpreso com o rumo de sua carreira), 'descomprometido', instigante, deliciosamente inventivo, refinado, desconcertante, subversivo, e escolasticamente sistemático. Parece seguir à risca a prescrição de da Vinci ("hostinato (sic) rigore") - instituído o rigor, segue-se uma liberdade positiva ${ }^{26}$, ou ainda, compartilha com Valéry a conviç̧ão de que "... as especulações feitas com rigor conduzam a mais estranhezas e perspectivas possíveis e inesperadas que a fantasia livre, que a obrigação de coordenar seja mais produtiva de surpresa do que o acaso". ${ }^{27}$

A peculiaridade da sua escritura-crítica reside precisamente nisso - a narrativa pessoal e idiossincrática beirando uma poética digressiva é pontuada por um pensamento sistemático cuja arquitetura precisa impõe as regras do método filosófico. Não escapa ao seu fado - a filosofia, inelutavelmente autoreflexiva, transfere ao seu objeto as estruturas próprias do pensamento. Esse briefing só reafirma o que assinalamos como um ponto fundamental da sua teoria, que é a disjunção entre filosofia e crítica de $\operatorname{arte}^{28}$, mas seu estilo ainda conserva os esclarecimentos e as análises exaustivamente meticulosas, típicas do filósofo analítico. Sob este aspecto pode ser considerado um "essencialista", no sentido de introduzir uma definição filosófica e um "historicista", no sentido de pressupor narrativas historicamente localizadas. Parece incontestável essa dupla abordagem irredutível a uma única perspectiva que o próprio autor 
declara: "Como um essencialista em filosofia compartilho da teoria de que a arte é sempre a mesma - que existem condições necessárias e suficientes para algo ser uma obra de arte invariáveis quanto ao tempo e o lugar. Mas como um historicista estou comprometido com a teoria de que o que é uma obra de arte num certo tempo não pode sê-lo em outro, e em particular que existe uma história, encenada através da história da arte, na qual a essência da arte - as condições necessárias e suficientes - dificilmente são trazidas à consciência". ${ }^{29}$ É por meio dessa disjunção estrutural do seu pensamento que pretende escapar a um certo tipo de crítica como "estética", que atribui às narrativas modernistas e particularmente à Greenberg com base na sua noção de "qualidade estética"

29. DANTO, After the End of Art. Op, Cit., p. 95 , cap. 5 . como um critério universal e homogenizador, e constitui assim um novo approch da filosofia da arte ao seu objeto. 